\title{
ACKNOWLEDGMENTS
}

The editor wishes to thank: Tristan Palmer, who commissioned this book as part of Berg's - now Bloomsbury's - design list and his successors Simon Cowell and Rebecca Barden who have overseen the development of this book; all of the authors whose work

is included here; and Nic Maffei, Jay and Laurel Lees-Maffei,

Kjetil Fallan, Steven Adams and Peter McNeil, for their help.

\author{
Bloomsbury Visual Arts \\ An imprint of Bloomsbury Publishing Plc \\ 50 Bedford Square \\ 1385 Broadway \\ London \\ New York \\ WC1B 3DP \\ UK \\ NY 10018 \\ USA \\ www.bloomsbury.com \\ Bloomsbury is a registered trade mark of Bloomsbury Publishing Plc \\ C) Grace Lees-Maffei, 2014 \\ John Smith has asserted his right under the Copyright, \\ Designs and Patents Act, 1988, to be identified as Author of this work.
}

All rights reserved. No part of this publication may be reproduced or transmitted in any form or by any means, electronic or mechanical, including photocopying, recording, or any information storage or retrieval system, without prior permission in writing from the publishers.

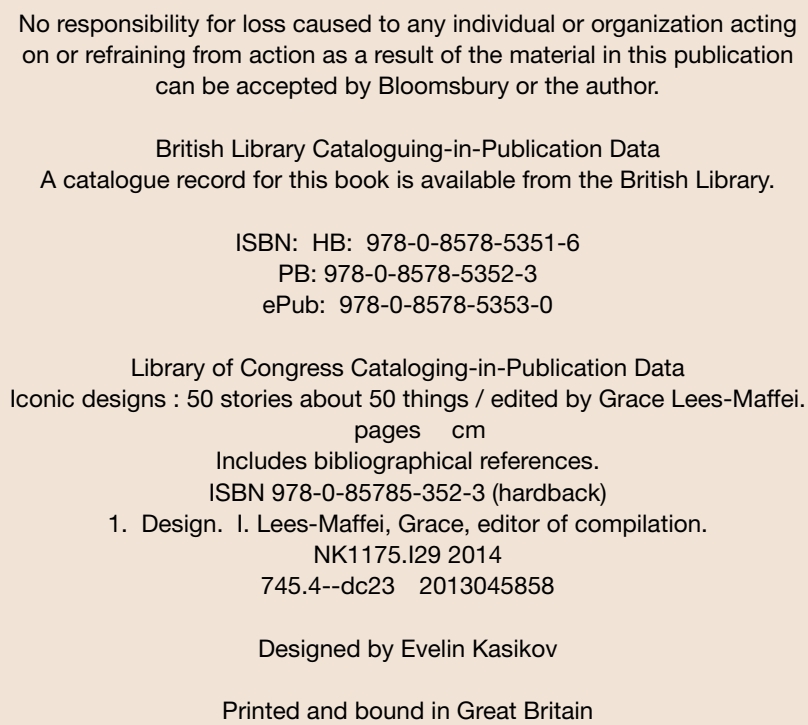




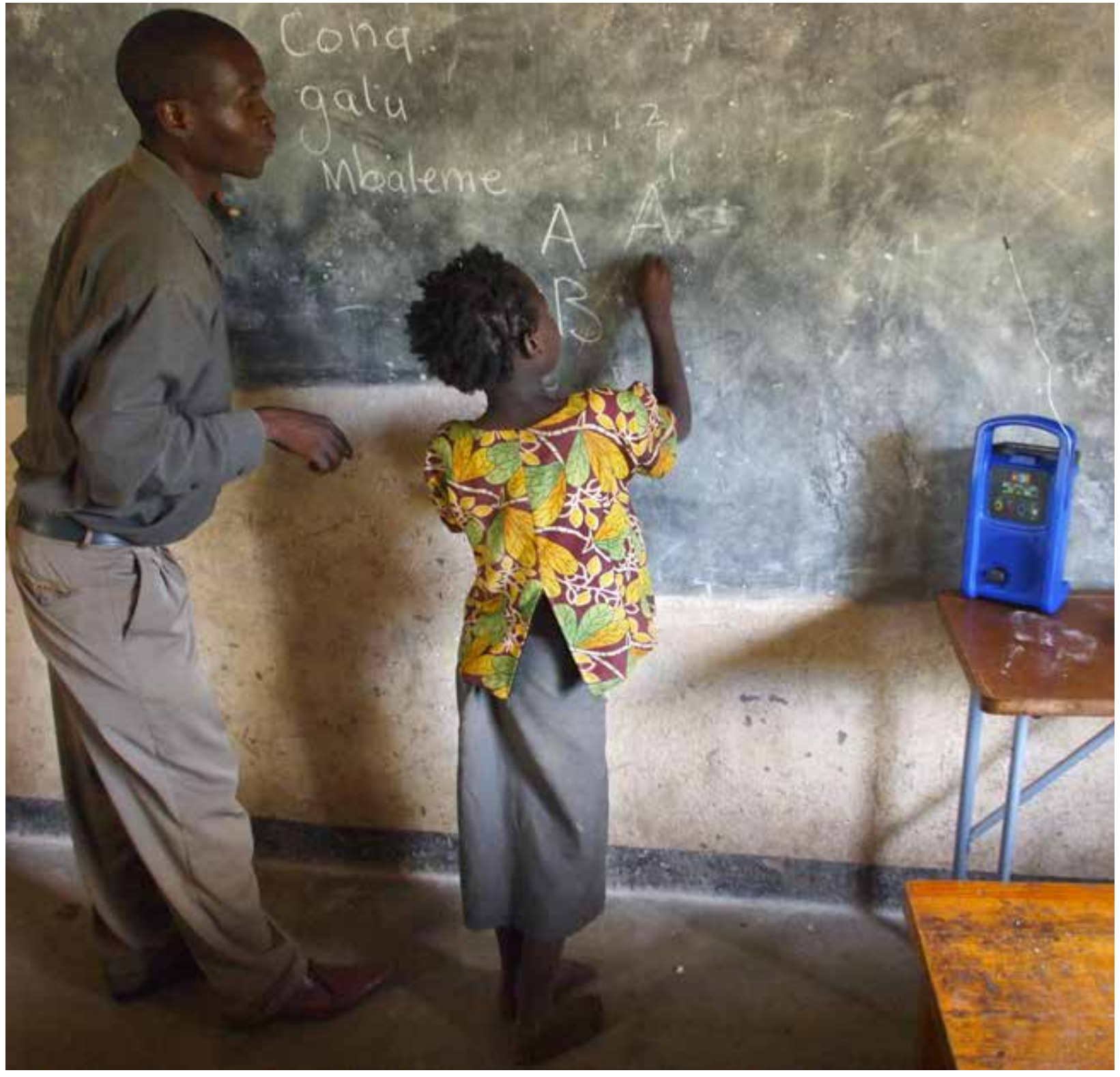

A schoolteacher using a Prime

radio, launched by Lifeline Energy in

2010, in rural eastern Zambia. Photo

courtesy Kristine Pearson, 2010. 


\title{
50
}

\section{Wind-Up Radio, UK/South Africa}

\section{(Trevor Baylis, 1992)}

\author{
Gabriele Oropallo
}

The wind-up radio originally conceived by British inventor Trevor Baylis OBE in 1991 is an example of successful interaction between invention, design, and social-minded enterprise. Baylis had already developed a series of products for disabled people called Orange Aids (1985) when he began work on a human-powered radio. The story of the development of the device is one of fruitful interplay between seemingly antithetical categories such as low-tech and high-tech, developed and developing world, and philanthropy and venture capitalism.

\section{Information and Empowerment}

The first inspiration for the invention of a clockwork radio came from a television show about the rapid spread of HIV/AIDS in Africa, broadcast by the BBC in September 1991. ${ }^{1}$ A major problem with the epidemic was the difficulty in reaching and communicating with large parts of the population. In many regions of the continent the only means of mass communication was radio broadcasting, but since these areas were off the grid and access to batteries was difficult for financial or logistic reasons, people were not able to hear news and advice aimed at curbing the spread of the epidemic. A communication device was necessary that could operate without relying on external power sources. In his autobiography, British inventor Trevor Baylis recounts how this problem made him think of the earliest phonographs, which used a hand crank to power a spring-wound mechanism and play music. Human-powered radio transmitters and receivers had in fact already been developed for use by the military in emergencies and survival situations. These devices, however, were bulky and complex pieces of machinery that would not be viable in the context of rural Africa. On the other hand, advances in transistor technology meant that contemporary wireless sets ran on much less power as compared with their thermionic-valve ancestors.

Baylis's approach to solving this problem involved imagining the challenges of daily life faced by the possible users of the product he had in mind and conceiving a somehow

1 See the sections of Trevor Baylis's autobiography dedicated to the Freeplay radio, Clock This: My Life as an Inventor (London: Headline, 1999), pp. 197-242.

2 On design thinking and the empathic approach to problem-solving, see Tim Brown, Change by Design (New York: HarperCollins, 2009).

3 Victor Papanek, Design for the Real World: Human Ecology and Social Change, 2nd revised edition (Chicago: Academy Chicago, 2005), p. 225. site-specific solution. ${ }^{2}$ The idea of bringing social inclusion and empowerment to the masses through design and technology was central in the most social-minded strands of modernist design. The question of a radio for the developing world had also been addressed by Victor Papanek, a designer who devoted the best part of his career to the promotion of socially and ecologically responsible design, especially through his book Design for the Real World, first published in 1971.

One of Papanek's first jobs after design school, according to his own account, was the design of a table radio. He later dismissed the assignment as mere 'shroud design', or 'appearance design', and, in contrast, included in his book a prototype of a 'radio receiver for the Third World' that he developed with George Seeger at North Carolina State College between 1962 and $1967 .^{3}$ The device employs a nonselective receiver housed in a used tin can and is powered by a slow fire fuelled by paraffin wax and wick. A variety of fuels can be used, including paper and cow dung. The manufacturing cost on a cottage-industry basis at the time Papanek was writing was merely 9 cents. 
4 StuartWalker reports examples of small appliances powered by fruits used as batteries in Sustainable by Design: Explorations in Theory and Practice (London: Earthscan, 2006), p. 163.

5 Stuart Walker, Sustainable by Design, $p$. 105.

6 BayGen's first radio was called 'Freeplay'. By 1998, the company had changed its name into Freeplay Energy Group. Today there are two companies called Freeplay, neither connected to the original enterprise. Freeplay Energy was sold in August 2008 to Indian businessman Devin Narang. Two years later, Freeplay Energy UK was placed into administration and later liquidation. Narang retained Freeplay Energy India, which focuses on lighting products. Euro Suisse International, a multinational manufacturer of home appliances, bought the assets of Freeplay Energy UK from the administrator and did a deal with Freeplay Energy India to use the brand.

7 A clockwork radio also appeared in Danny Boyle's 28 Days Later (2002), a film that, with its story of pandemics and emergency broadcasts, curiously reflects some aspects of the Freeplay's genesis.
Papanek's and Seeger's prototypes are examples of an involvement with material culture and technology that goes beyond the surface level of the object and, while tinkering with the inside workings of the product, generates invention. However, like other examples of radios and small devices powered by biological electrochemical means, ${ }^{4}$ it functions best as a conceptual piece of design, a 'contemplative act' more effective from the educational and critical perspective than as a viable solution. It is a 'visual myth', as design writer Stuart Walker would put it. ${ }^{5}$

After watching the BBC show, Baylis began experimenting with a transistor radio, a small electric motor taken from a toy car and a hand brace. He then added a gearbox that allowed a logarithmic spring to be wound and unwind to power a small generator. The logarithmic spring soon revealed itself as insufficient to produce a constant and controlled flow of electricity for longer than a dozen minutes. Baylis's intuition was to substitute it with a constant force spring of the same kind typically used in seatbelt systems. He patented the idea on 19 November 1991 and set out to get the radio into production. However, because of the technical limitations of the prototype, interest from the manufacturers approached by Baylis was lukewarm at best. The UK Design Council rejected Baylis's support request arguing that the technology employed by the radio was too low-tech for the potential of the British industry and suggested the product would be best suited marketing in the developing world.

In fact, television would be pivotal in the development of the clockwork radio after providing the initial input for Baylis's creativity. In 1993, the prototype was featured on a popular BBC program about technological innovation, Tomorrow's World. The segment attracted the interest of two businessmen, British accountant Christopher Staines and South African entrepreneur Rory Stear, who immediately recognized the idea's potential and the social and economic implications it could have in post-Apartheid South Africa. Their involvement gave credibility to the project and provided access to the much-needed technical expertise necessary to its development. Together, they were able to secure funding from the UK Overseas Development Agency, as well as the Liberty Life Foundation. The funding allowed them to pay for consulting on the radio's gearbox from the Department of Electronic Engineering at Bristol University and to set up the first BayGen (short for Baylis Generators) plant in Cape Town, South Africa, in $1995 .^{6}$

Market research in Africa concluded that potential customers were interested in a sizeable, heavy, and robust product that could reach sufficiently loud volumes for listening in a big group and while on the job. Mechanical engineer David Butlion and industrial designer Andy Davey of TKO studio (UK) were hired to incorporate these features in the Freeplay (later known as FPR1), the first device based on Baylis's patent, manufactured in a factory that mostly employed disabled people.

The FPR1, now out of production, was powered by a 10-metre-long heavy carbon spring, carefully enclosed in a heavy-duty casing to avoid accidental injury. The radio provided 25 minutes of playing time for 60 winds and had a lifespan of around 10,000 spring cycles, that is between 4,000 and 5,000 hours of operation, after which the spring would start to decay irreversibly. In July 1996, the FPR1 was selected as Best Product and Baylis and Davey as Best Designers at the BBC Design Awards. The radio received a great amount of exposure in mainstream media ${ }^{7}$ and its inventor became a regular television personality. In 1997, he was awarded the Order of the British Empire and the President's Medal from the UK Institute of Mechanical Engineers.

In 1998, the radio was redesigned by Roelf Mulder, Byron Qually and Etienne Rijkheer of ...XYZ Design (South Africa) and given a smaller, transparent body. The FRP2 had a run time of up to one hour with a mere thirty-second wind. This version of the radio, while 
almost completely developed in Africa, was designed and marketed with the Western consumer market in mind. Other human-powered devices later developed by the company include flashlights and a wind-up mobile phone charger. The nonprofit Freeplay Foundation, established in 1999 and led by Kristine Pearson, was important in gathering the field knowledge necessary to the design of the Lifeline, a new series of devices that also feature an additional solar panel to lessen the need for winding. In 2010, the Freeplay Foundation changed its name to Lifeline Energy and launched the Prime, a digital media player particularly helpful in formal and informal education. To date, humanitarian programmes run by the UN and EU have distributed large numbers of human-powered radios as part of their development cooperation efforts or after natural disasters, and Lifeline Energy successfully established their social model with listening groups gathering around radios entrusted to 'guardians' who are responsible for the device.

\section{Human-Powered Sound and Vision}

While the original FRP1 only stored energy mechanically, using the uncoiling of the spring as source of power, later Freeplay products contain rechargeable battery packs made with substances that can be environmentally hazardous if not recycled or disposed of properly. The constant force spring eventually disappeared from the mechanics of the radio so that it could store more power and offer better safety and serviceability.

In any case, the impact of the original clockwork radio idea went well beyond the development of consumer devices, however unique it might have been in its context. The wind-up radio was conceived as a means to provide access to information and was extensively used as an educational device. The radio is iconic also because it represented a sort of postmodern take on human muscle power as a source of energy, an object in which categories like low and high technology constantly overlap and intermingle. Disconnected from the immediacy of manual labour, human movement presented itself in a new light. Just like solar, wind, or other alternative sources of energy, muscle power can be easily transformed, or stored and postponed. The kinetic energy of everyday movements like those of the crowds of commuters gathering on a platform of the London Tube or the pounding of the feet on a dance floor are today all being studied in order to develop microgenerators that can harvest their power and re-use it locally.

In the case of the wind-up radio, invention made possible a conceptual leap from contemplative act to viable product. In the process, layers of meaning accrued to the object, information about the connections between us and the world we inhabit. When abstractions are seamlessly made visible and experiential, meaning is reified and a design becomes iconic. The energy-harvesting technology that moves the dynamo and powers the receiver and speaker of a device like the wind-up radio is always educational. It is educational by showing rather than telling. Through the form and function of an iconic object like the wind-up radio, relations are made tangibly material and the system is left open like a conversation to include the user. Cranking a hand brace produces information, education and entertainment. The message could not be more subtle in its simplicity. It tells a story of beautiful, eternal principles of physics explaining how energy never disperses and fade away, but is always converted from one form into another. 